\title{
In situ Observation of Polymorphic Transition during Crystallization of Organic Compounds Showing Preferential Enrichment by Means of Temperature-Controlled Video-Microscopy and Time-Resolved X- Ray Powder Diffraction
}

\author{
Hiroki Takahashi, ${ }^{* 1}$ Sekai Iwama, ${ }^{2}$ Simon Clevers, ${ }^{3}$ Stéphane Veesler, ${ }^{4}$ Gérard Coquerel, ${ }^{3}$ Hirohito Tsue, \\ Rui Tamura ${ }^{1}$ \\ ${ }^{1}$ Graduate School of Human and Environmental Studies, Kyoto University, Kyoto 606-8501, Japan \\ ${ }^{2}$ Faculty of Law, Meijigakuin University, Minato-ku, Tokyo 108-8636, Japan \\ ${ }^{3}$ Normandie Université, SMS, EA 3233, Univ Rouen, Crystal Genesis Unit, 76821 Mont Saint-Aignan Cedex, France \\ ${ }^{4}$ CINaM-CNRS, Aix-Marseille Université, Campus de Luminy, F-13288 Marseille, France
}

\begin{abstract}
A solvent-assisted solid-to-solid polymorphic transition, which was assumed to be one of the key processes for the occurrence of preferential enrichment (PE), has been proved to occur by means of temperature-controlled video-microscopy (TCVM) and time-resolved in situ X-ray powder diffraction (XRPD) measurement during crystallization of two typical first-generation of chiral racemic compounds (1 and 2) showing an excellent PE phenomenon.
\end{abstract}

\section{INTRODUCTION}

Preferential enrichment (PE) is a unique spontaneous enantiomeric resolution phenomenon applicable to racemic crystals; by repeating simple recrystallization of a certain kind of racemic crystals under nonequilibrium conditions at high supersaturation, alternating enrichment of two enantiomers occurs largely in the mother liquor and slightly in the deposited crystals with full reproducibility (Figure 1a). ${ }^{1,2}$ This phenomenon, which contrasts with the well-known preferential crystallization of racemic conglomerates composed of a mixture of homochiral $R$ and $S$ crystals, ${ }^{3,4}$ originates from regular chiral fluctuation or symmetry breaking after the polymorphic transition of an incipient metastable polymorphic form into a thermodynamically more stable form during crystallization from the highly supersaturated solution of a certain kind of racemic crystals (Figure S1) ${ }^{5-10}$ Thus, the mechanism of PE has been interpreted in terms of a nonlinear complexity phenomenon including two unique processes: a solvent assisted solid-to-solid polymorphic transition and subsequent selective redissolution into the mother liquor of the excess one enantiomer from the transformed disordered crystals. ${ }^{11-21}$

With respect to the second process, the kinetic and thermodynamic origin has been unveiled in terms of the unique nonlinear solubility properties of the two enantiomers after the occurrence of polymorphic transition under PE crystallization conditions using high supersaturation, together with the ternary phase diagram that is consistent with the mechanism of PE. ${ }^{22,23}$ As to the first process, we have judged the occurrence of polymorphic transition during crystallization indirectly by the in situ ATR-FTIR spectroscopy which can detect a change in the hydrogen bonding mode in small particles $(<$ ca. $1 \mu \mathrm{m} \phi)$ as well as both solute and solvent molecules. By comparing the IR spectrum just before crystallization with that after crystallization, we predicted the occurrence of polymorphic transition. ${ }^{11-}$ ${ }^{21}$ However, some compounds showing an excellent PE phenomenon failed to give an appreciable IR spectral change during crystallization, due most likely to a small change in the hydrogen bonding mode upon the polymorphic transition. Therefore, the use of other in situ techniques to observe polymorphic transition directly during crystallization was indispensable. (a)

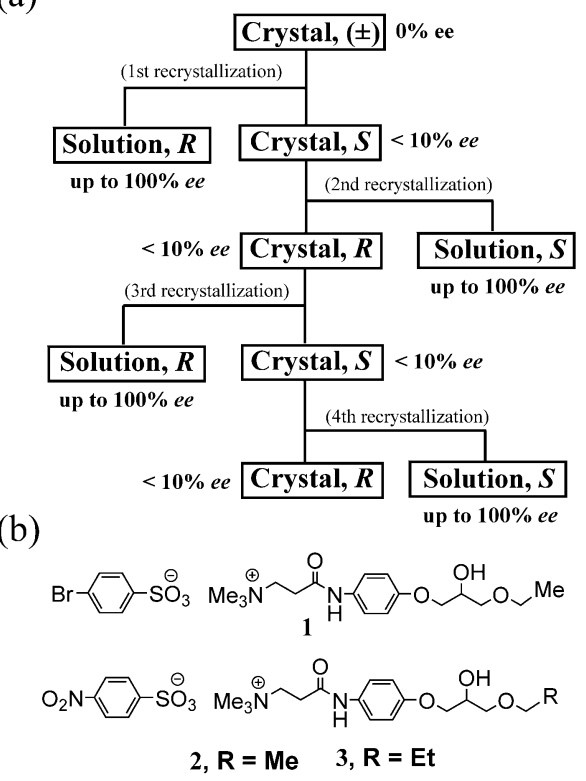

Figure 1. (a) Features of preferential enrichment (PE) of a racemic crystal in case of substantial enrichment of $(R)$ enantiomer in the mother liquor after the first recrystallization of chiral racemic organic compounds. (b) Molecular structures of $\mathbf{1}$ and $\mathbf{2}$ showing PE, and $\mathbf{3}$ failing to show it.

Here we report the successful direct observation of polymorphic transition during crystallization by the combined use of temperature-controlled video-microscopy (TCVM) $)^{24,25}$ and time-resolved in situ XRPD measurement ${ }^{26}$ under PE conditions with regard to typical first-generation of organic compounds, $\mathbf{1}$ and $\mathbf{2}$ (Figure 1b), for which the PE behavior, and the crystal structure and physicochemical properties of the deposited stable $\delta$ form crystal were fully characterized. ${ }^{5,6}$

\section{EXPERIMENTAL SECTION}

General. Melting points were measured by differential scanning calorimetry (DSC) at the scanning rate of $5^{\circ} \mathrm{C} / \mathrm{min}$. 
The in situ Fourier transform infrared (FTIR) spectra were recorded in solution and suspension by using the attenuated total reflection (ATR) method on ReactIR $45 \mathrm{~m}$. XRPD patterns were recorded at a continuous scanning rate of $1^{\circ} 2 \theta / \mathrm{min}$ using $\mathrm{Cu}$ $\mathrm{K} \alpha$ radiation $(40 \mathrm{kV}, 40 \mathrm{~mA})$ with the intensity of the diffracted $\mathrm{X}$-ray being collected at intervals of $0.02^{\circ} 2 \theta$. A graphite monochromator was used to remove $\mathrm{Cu} \mathrm{K} \beta$ radiation.

Experimental setup of TCVM. The homemade apparatus (ANACRISMAT) used is shown in Figure 4. We used standard HPLC glass vials as an observation cell containing $1 \mathrm{~mL}$ of solvent. The cell was inserted into the temperature controlled unit thermostatted by Peltier elements and observed by a microscope (Nikon Eclipse TE2000-U). Sequential image acquisitions were performed from minutes to hours.

Experimental setup of in situ XRPD measurement. In situ XRPD data were collected using a homemade prototype diffractometer (Figure S3). ${ }^{27}$ This apparatus has an original goniometer with an inverted geometry $(-\theta /-\theta)$. Its association with a dedicated reactor, with a transparent bottom to X-rays, provides the possibility to identify solid(s) in suspension, all along a crystallization process (time and temperature dependent), without any sampling. The detector is a LYNXEYE ${ }^{\mathrm{TM}}$ (Bruker, Germany) and the beam (Ni filtered) comes from an X-ray tube with a copper anticathode. The in situ XRPD measurement was carried out at a 9 min interval for the first $225 \mathrm{~min}$ and at a $240 \mathrm{~min}$ interval from 225 to $1300 \mathrm{~min}$.

Preparation of samples. In the case of TCVM: Racemic 1 $(100 \mathrm{mg})$ was dissolved in a mixture of EtOH and 2-PrOH (1/1 $\mathrm{v} / \mathrm{v}, 1 \mathrm{~mL}$ ) by heating to give a 10 fold supersaturated solution (versus the solubility at $20^{\circ} \mathrm{C}$ ), while $2(64.9 \mathrm{mg}$ ) was dissolved in EtOH $(1 \mathrm{~mL})$ by heating to give a 20 fold supersaturated solution. The resulting solution was filtrated through a $0.45 \mu \mathrm{m}$ membrane filter to remove any invisible microcrystals and pour into the observation cell. The cell was set in the temperature control unit preheated at $60^{\circ} \mathrm{C}$. The cell temperature was cooled and kept at $20^{\circ} \mathrm{C}$ until crystallization began.

\section{RESULTS AND DISCUSSION}

Crystal structures and melting point diagrams. Racemic crystals of both $\mathbf{1}$ and $\mathbf{2}$ are classified as a "mixed crystal" (i.e., solid solution) composed of two enantiomers. Their stable racemic crystal structures are almost identical and are called a $\delta$ form (Figure S2). Only difference between them is that one hydroxy group attached to the asymmetric carbon atom is orientationally disordered for racemic 1 (occupancy factor: 67/33), whereas such a disorder was not noted for racemic 2 . The $\delta$ form crystals are most commonly found for the first-generation compounds showing PE. It was proposed that polymorphic transition of the initially formed metastable $\gamma$-form into the stable $\delta$-form was essential for the occurrence of PE (Figure S2), because the $\gamma$-form crystal structure was very often observed as a stable form for analogous compounds, such as racemic $\mathbf{3}$ which failed to show PE. ${ }^{5,11-15}$ As an example to support this hypothesis, we observed that the polymorphic transition of a $\gamma$ form into another form suddenly occurred to induce PE and since then the $\gamma$-form was never obtained. ${ }^{7}$

The melting point diagrams of $\mathbf{1}$ and $\mathbf{2}$ were previously constructed by differential scanning calorimetry (DSC) analysis (Figure 2). ${ }^{5,6}$ The measured samples were prepared in a kinetically controlled manner so that the obtained crystalline samples should contain both the metastable and stable forms. The diagram for 1 showed two flat convex curves (standing for two couples of liquids and solids; the one at low temperatures corresponding to the metastable phase $\gamma$ ); at the initial stage of crystallization two endothermal peaks were observed by DSC analysis for crystals of less than $30 \%$ ee and more than $80 \%$ ee but not in the range of $40-70 \%$ ee. These results indicate that the two curves correspond to a mixed crystal composed of two enantiomers (Figure 2a). On the other hand, for $\mathbf{2}$, the two phase curves intersect at two points around $35 \%$ ee; one steep curve in the range of less than $35 \%$ ee corresponded to a non-stoichiometric racemic compound, and the other flat one in the range of more than $35 \%$ ee was assigned to a mixed crystal of two enantiomers (Figure 2b). (a)

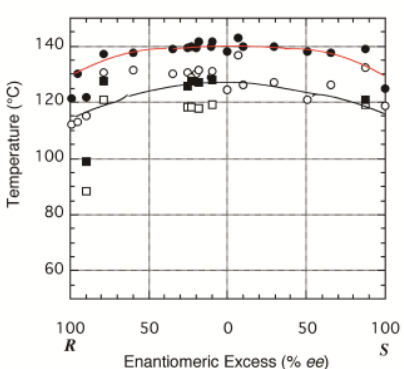

(b)

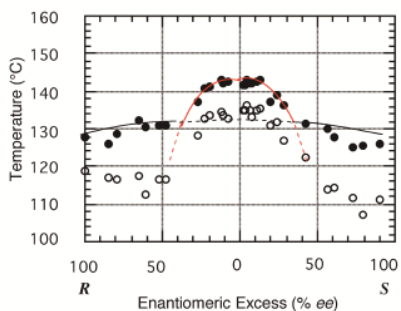

Figure 2. Melting-point diagrams of (a) 1 and (b) 2. White and black circles represent the temperatures of the beginning and the end of fusion of the stable polymorph, respectively, while white and black squares in panel (a) are those of the metastable polymorph. Data cited from refs 5 and 6.

In situ ATR-FTIR measurement. We previously proposed the mode of the $\gamma$-to- $\delta$ polymorphic transition during crystallization for racemic 2 by means of the in situ ATR-FTIR measurement (Figure 3a). ${ }^{5}$ In the present study, we measured the in situ ATR-FTIR spectra for racemic $\mathbf{1}$ in the range of $1260-1160 \mathrm{~cm}^{-1}$ corresponding to S-O stretching vibrations during crystallization and the obtained spectra were compared with those of racemic $\mathbf{2}$. The spectra of $\mathbf{2}$ changed for the first $90 \mathrm{~min}$, whereas no appreciable spectral change was noted for $\mathbf{1}$ during the whole crystallization process (Figure $3 \mathrm{~b}$ ). We suggested that polymorphic transition, which was induced by rearrangement of hydrogen bonds, occurred fast enough to be detected by the in situ IR spectroscopy for racemic 2 , whereas that of racemic 1 was too slow to be detected and/or involved no drastic change around the sulfonate ion during crystallization. These results may be associated with the ordered or fairly disordered $R$ and $S$ molecular arrangement in the resulting deposited crystals of $\mathbf{2}$ or 1, respectively. Nevertheless, since the stable crystal structures of racemic $\mathbf{1}$ and $\mathbf{2}$ were almost identical, the polymorphic transition of $\mathbf{1}$ is most likely to be a $\gamma$-to- $\delta$ type, too. To confirm whether racemic $\mathbf{1}$ and $\mathbf{2}$ show a similar type of polymorphic transition during crystallization, we performed the TCVM and time-resolved in situ XRPD observation for their crystallization. 
(a)

(b)
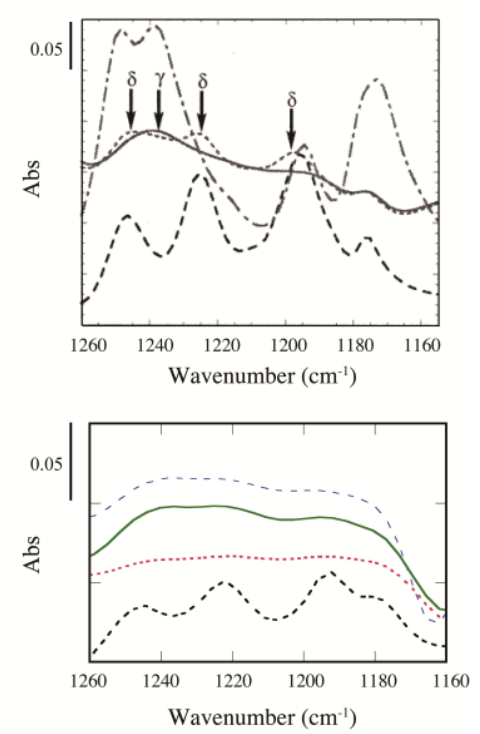

Figure 3. (a) In situ ATR-FTIR spectra during crystallization from a 20 fold supersaturated EtOH solution of racemic 2, cited from ref 3. Comparison of spectra at the beginning (solid line, - ) and the end (dotted line, $\cdots$ ) of crystallization with the spectra in the solid state of racemic 2 (dashed line, ---, $\delta$-form crystal structure) and racemic 3 (dashed and dotted line, -.- --, $\gamma$-form crystal structure). Black arrows indicate the absorptions corresponding to the $\delta$ - or $\gamma$-form supramolecular structure. (b) In situ ATR-FTIR spectra during crystallization from the 10 fold supersaturated solution of racemic $\mathbf{1}$ in a mixture of EtOH and 2-PrOH (1/1 v/v). Comparison of spectra in solution (blue broken line, - - ) just before crystallization, in the suspensions at the beginning (green solid line, - -) and the end (red dotted line, $\cdots$ ) of crystallization, and in the solid-state (black dashed line, ---, $\delta$-form crystal structure).

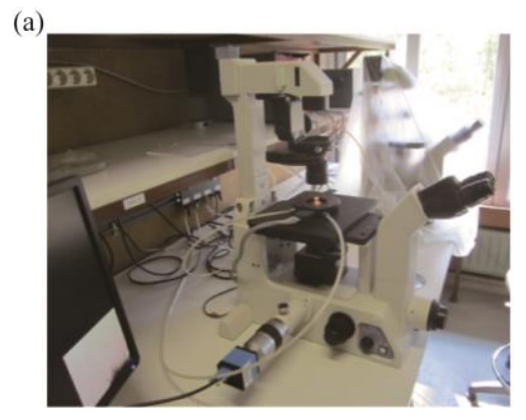

(b)

(c)
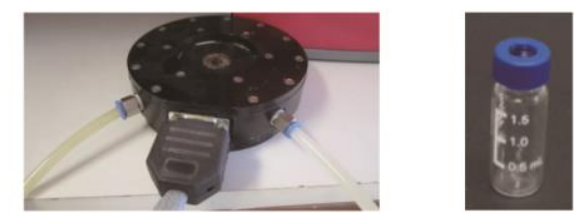

Figure 4. A temperature controlled video microscope. (a) Overview, (b) a temperature control unit and (c) an observation cell.

Temperature-controlled video-microscopy (TCVM). By using the optical video microscope connected to a temperature controller between 0 and $80{ }^{\circ} \mathrm{C}$ (Figure 4), we could continually observe not only the crystallization process by cooling but also the dissolution behavior of the deposited crystals by heating.

In the case of $\mathbf{1}$, the racemic crystals were dissolved in a mixture of ethanol and 2-propanol $(1 / 1 \mathrm{v} / \mathrm{v})$ by heating to give a 10 fold supersaturated solution (vs its solubility at $20^{\circ} \mathrm{C}$ ). The resulting hot solution $\left(60 \sim 70{ }^{\circ} \mathrm{C}\right)$ was filtered through $0.45 \mu \mathrm{m}$ membrane filter and the filtrate was poured into the observation cell pre-warmed at $60{ }^{\circ} \mathrm{C}$ (Figure 4c). Then the cell was cooled and kept at $20^{\circ} \mathrm{C}$ until crystallization began. First transparentleaf-shaped crystals were deposited, and second crystals with a dendritic habit appeared by heterogeneous nucleation onto the leaf-shaped crystals and gradually grew (Figure 5a, b and Movie S1). (a)

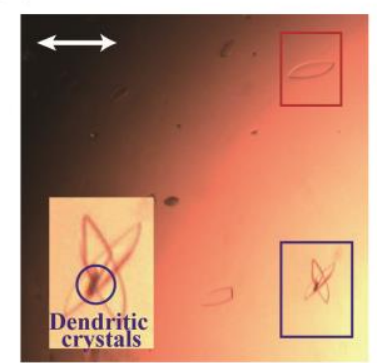

(c)

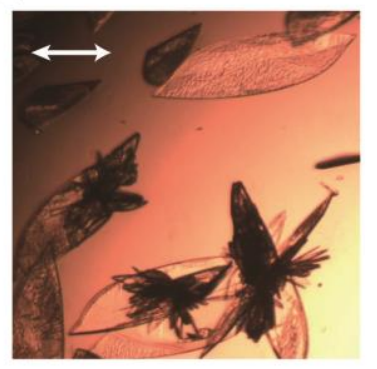

(b)

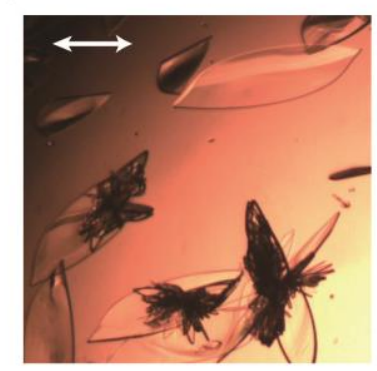

(d)

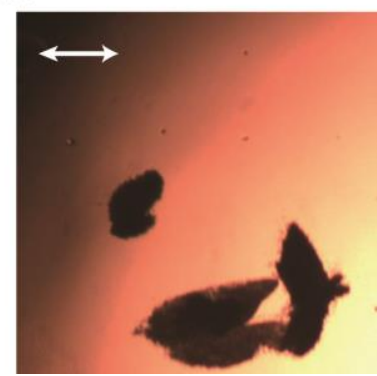

Figure 5. Time sequence showing microscope images of racemic 1 during crystallization from the 10 fold supersaturated $\mathrm{EtOH} / 2-\mathrm{PrOH}(1 / 1 \mathrm{v} / \mathrm{v})$ solution at $20^{\circ} \mathrm{C}$. (a) $\mathrm{t}=4 \mathrm{~s}$ in Movie $\mathrm{S} 1$; the metastable leaf-shaped and the stable dendrite crystals nucleated onto the leaf-shaped crystals are highlighted as red and blue squares, respectively. The left-side inset indicates the magnification of the right-side crystals. (b) $t=33 \mathrm{~s}$; the stable crystals grow on the surface of the metastable crystals. (c) $t=$ $37 \mathrm{~s}$; the metastable crystals started to dissolve when the solution was heated to $70{ }^{\circ} \mathrm{C}$. d) $\mathrm{t}=45 \mathrm{~s}$; dissolution of leaf-shaped and stable dendrite crystals. The white arrow corresponds to 50 $\mu \mathrm{m}$.

To examine whether the first and second generation of crystals are the same polymorph or not, the suspension containing both crystal habits was gradually heated up to $70{ }^{\circ} \mathrm{C}$ (Figure $5 \mathrm{c}$ and $\mathrm{t}=37 \mathrm{~s}$ in Movie S1). At the first stage, the leaf-shaped crystals changed from clear to opaque (the transition lasts for 2 $\mathrm{s}$ from $\mathrm{t}=37 \mathrm{~s}$ in Movie S1), keeping its habit and size, due to a solid-state phase transition (SSPT). If it were a solution-mediated phase transition (SMPT), we should observe the dissolution of the metastable phase and nucleation of the stable phase. However, crystals keep their leaf habit and the speed of the phase transition is in agreement with the assumption that SSPT is faster than SMPT. At the second stage, all crystals with leaf and dendritic habits dissolved $(\mathrm{t}=66 \mathrm{~s}$ in Movie $\mathrm{S} 1)$. This crystallization and dissolution process was reproducible. Thus, it 
has been confirmed that the first formed clear leaf-shaped crystals are a metastable form and the second dendrites are a stable form. Furthermore, it is noteworthy that the initial formation of metastable leaf-shaped crystals followed by a polymorphic transition was fully reproducible and the stable dendrites never acted as the crystal seed to grow the same form.

In the case of racemic $\mathbf{2}$, a similar crystallization and dissolution process was reproducibly observed starting from a 20 fold supersaturated ethanol solution at $20{ }^{\circ} \mathrm{C}$. As soon as the metastable tiny leaf-shaped crystals formed, the stable dendrites nucleated and grew onto the surface of the metastable crystals at $20{ }^{\circ} \mathrm{C}$ (Figure $6 \mathrm{~b}$, Movie S2). When the temperature was increased to $70{ }^{\circ} \mathrm{C}$ (Movie S3), we observed the dissolution of leaf-shaped crystals followed by that of dendritic crystals, similar to the case of racemic $\mathbf{1}$.

Thus, we could confirm the presence of two polymorphs for racemic $\mathbf{1}$ and $\mathbf{2}$ by TCVM observation. Both compounds showed a similar crystallization and dissolution behavior. (a)

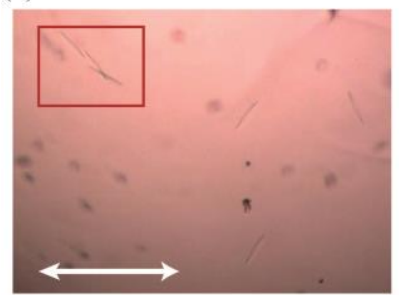

(c)

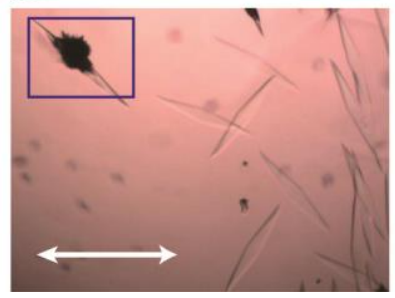

(b)

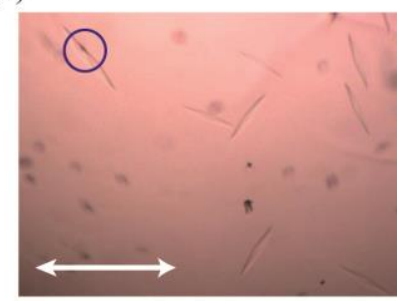

(d)

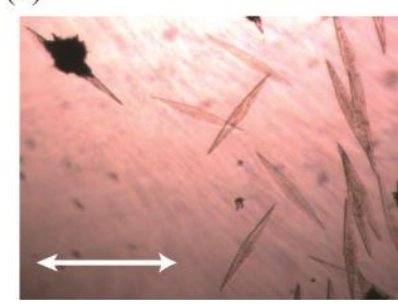

Figure 6. Time sequence showing microscope images of racemic 2 during crystallization from a 25 fold supersaturated $\mathrm{EtOH}$ solution at $20{ }^{\circ} \mathrm{C}$. (a) $\mathrm{t}=9 \mathrm{~s}$ in Movie S2; the metastable leafshaped crystal is highlighted as a red square. (b) $t=20 \mathrm{~s}$; the stable dendrite crystals nucleated on leaf-shaped crystal are highlighted as a blue circle. (c) $\mathrm{t}=47 \mathrm{~s}$; the stable dendritic crystals grown onto the surface of the metastable crystal are highlighted as a blue square . (d) $t=64 \mathrm{~s}$; leaf crystals started to dissolve when the solution was heated to $70{ }^{\circ} \mathrm{C}$. The white arrow corresponds to $50 \mu \mathrm{m}$.

Time-resolved in situ XRPD measurement. We used the in situ XRPD apparatus with a modified optical system to observe the deposited crystals on the bottom of the vessel (Figure 7). A double-jacketed vessel with an observation cell and a thermostat to control the solution temperature by circulating the coolant was used (Figure S3).

The preliminary time-resolved in situ XRPD measurement was carried out for racemic $\mathbf{1}$ and $\mathbf{2}$ under the PE crystallization conditions. The experimental results indicated that the deposited crystals of $\mathbf{1}$ exhibited sufficient diffraction intensities, whereas the diffraction intensities of 2 were too low due to the absence of a heavy atom in the molecule. The optimal crystalli- zation conditions for the in situ XRPD measurement for racemic 1 were determined; starting from a 11 fold supersaturated $\mathrm{EtOH} / 2-\mathrm{PrOH}(1 / 1 \mathrm{v} / \mathrm{v})$ solution at $10{ }^{\circ} \mathrm{C}$ without stirring. (a)

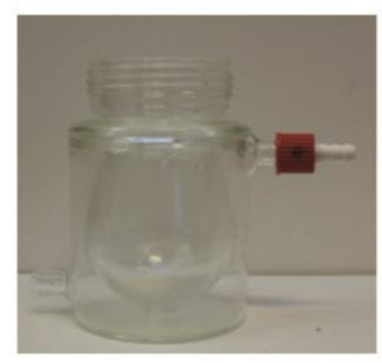

(c)

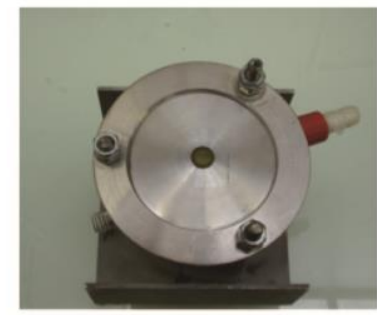

(b)

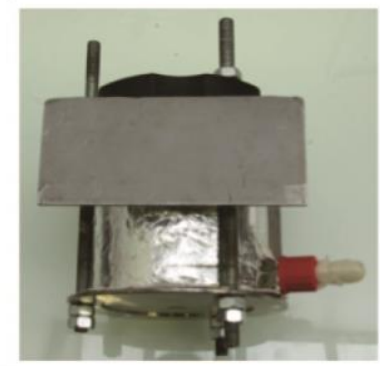

(d)

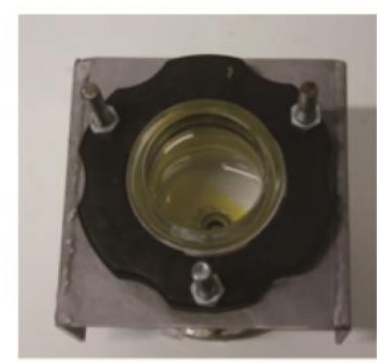

(e)

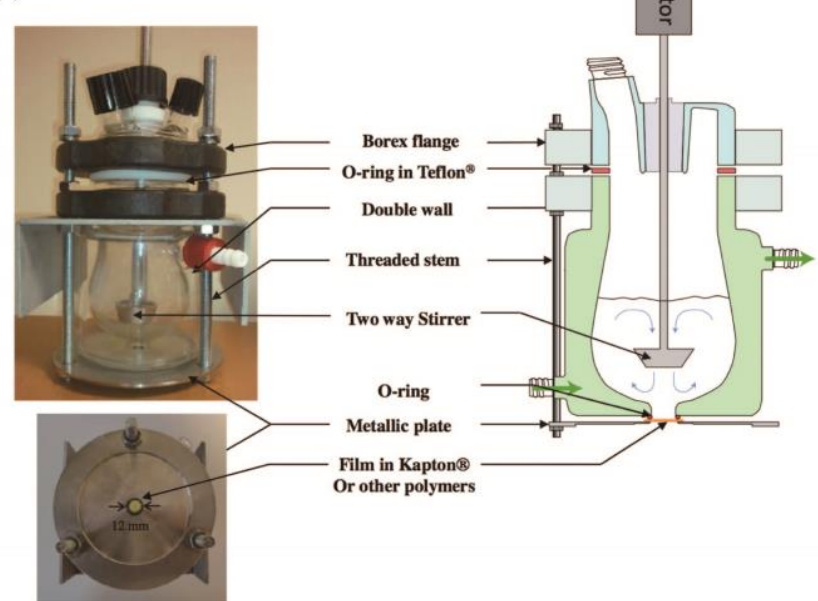

Figure 7. Observation cell (double jacketed vessel) wrapped with insulating material. (a) Side view without insulating material, (b) side view with insulating material, (c) bottom view, (d) top view, and (e) overview. In this experiment, the bottom hole was covered by KAPTON® thin film $(7.5 \mu \mathrm{m})$.

With respect to the time-resolved XRPD patterns for racemic 1, major transition points are denoted by arrows 1-3 in Figure 8. First crystals were detected (arrow 1 in Figure 8) 9 min after the beginning of the experiment. Between the $4^{\text {th }}$ and $5^{\text {th }}$ scans (between 36 and $45 \mathrm{~min}$, arrow 2), a polymorphic transition occurred, which should correspond to the nucleation and crystal growth of stable dendrite crystals onto the metastable leaf-shaped crystals observed by TCVM at $20^{\circ} \mathrm{C}$. Between the $6^{\text {th }}$ and $9^{\text {th }}$ XRPD patterns (arrow 3), it is difficult to conclude on the exact nature of the solid phase(s). One has to keep in mind that these XRPD patterns are collected under stagnant conditions. Therefore, strong preferential orientation effects could occur (i.e. modifications of peak intensities). Moreover, maturation of the phase can occur which could additionally 
change the crystallinity and the shape of the particles. After 90 minutes $\left(10^{\text {th }} \mathrm{scan}\right)$, the subsequent evolution seems to consist in a simple maturation of the final $\delta$-phase (Figure S4a). This maturation does not show any sign of further evolution after 465 minutes (Figure S4b). After the last measurement, the deposited crystals were separated from the solution and the conventional powder XRPD measurement was carried out. The powder pattern simulated from the single crystal data $(\delta$-form) of racemic 1 was identical to this experimental pattern (Figure 8). However, due to a limited number of diffraction peaks, the determination of the lattice parameters of the metastable crystal was not successful.

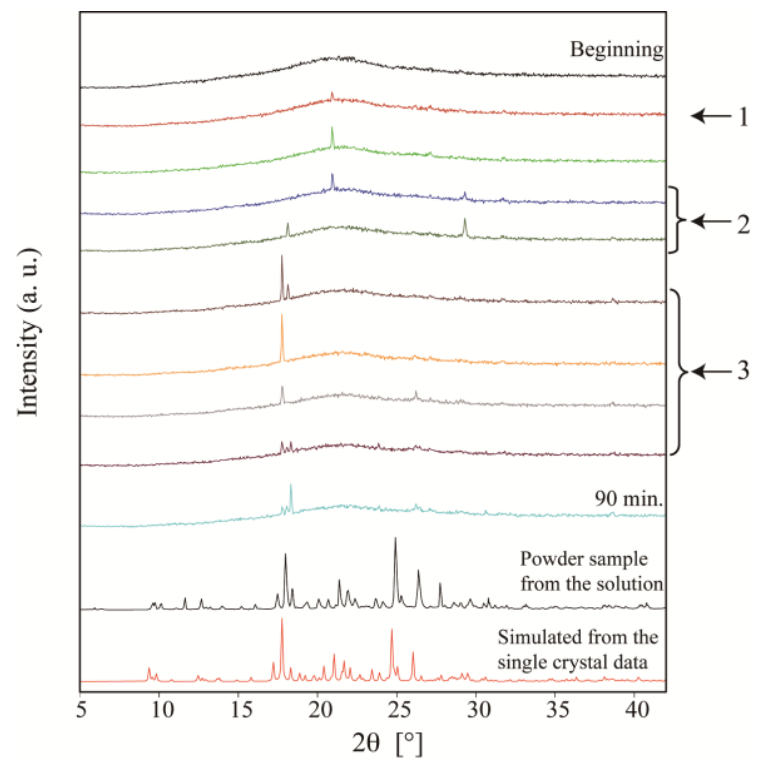

Figure 8. In situ XRPD patterns of 1. Conditions: In EtOH/2$\mathrm{PrOH}\left(1 / 1 \mathrm{v} / \mathrm{v}, 11\right.$ fold supersaturation), at $10{ }^{\circ} \mathrm{C}$, and time interval $9 \mathrm{~min}$. These in situ diffraction patterns were compared with that of the dry final powder sample and that simulated from the single crystal data ( $\delta$-form) of racemic 1 . Since the crystallization should be induced by the KAPTON ${ }^{\circledR}$ thin film used as a cover of the observation window, crystallization upon this in situ XRPD measurement was faster than that upon the TCVM observation.

\section{CONCLUSIONS}

By using both TCVM and time-resolved in situ XRPD measurement, we have clearly observed the crystal growth and polymorphic transition processes during crystallization for two typical first-generation of chiral racemic organic compounds (racemic 1 and 2) showing PE. The TCVM observation of both compounds indicated that the metastable transparent-leafshaped crystals were formed first, followed by a heterogeneous nucleation of the stable form onto the surface of the first-formed crystals to give the second stable dendritic crystals. We clearly evidenced a solid-state phase transition in one case (racemic 1). This mode of polymorphic transition has turned out to differ from our speculation that the transition might occur inside each crystal. By the time-resolved in situ XRPD measurement for racemic 1 , the drastic diffraction pattern change corresponding to the polymorphic transition of the metastable $\gamma$-form to the stable $\delta$-form was observed in conformity with the TCVM observation.

By the combined use of three real-time methods (in situ ATR-IR spectroscopy, TCVM, and time-resolved in situ XRPD measurement), we can obtain various information on a crystallization process, i.e., changes in intermolecular interaction, morphology and crystal lattice. The in situ ATR-IR spectroscopy is useful in the case that relatively fast polymorphic transition occurs with a drastic rearrangement of hydrogen bonds. The TCVM is a valuable method to observe the dissolution behavior of the deposited crystals at elevated temperatures as well as the crystallization process at lower temperatures. The timeresolved in situ XRPD measurement provides a decisive proof of polymorphic transition. It is highly desired that the determination of the lattice parameters of metastable forms becomes feasible by using the in situ XRPD data.

\section{ASSOCIATED CONTENT}

\section{Supporting Information Available.}

General mechanism of PE (Figure S1); schematic representation of the intermolecular interactions in the $\delta$ - and $\gamma$-form crystals (Figure S2); an overview of in situ X-ray diffractometer (Figure S3); in situ XRPD patterns of 1 from $90 \mathrm{~min}$ to 1300 min (Figure S4); TCMV movies for crystallization of 1 (Movie S1) and 2 (Movies S2 and S3). The Supporting Information is available free of charge on the ACS Publication website at DOI:

\section{AUTHOR INFORMATION}

\section{Corresponding Author \\ takahashi.hiroki.2x@kyoto-u.ac.jp}

\section{ACKNOWLEDGMENT}

This work was supported by JSPS KAKENHI Grant Number 26248024.

Supporting Information Available: General mechanism of PE (Figure S1); schematic representation of the intermolecular interactions in the $\delta$ - and $\gamma$-form crystals (Figure S2); Overview of in situ X-ray diffractometer (Figure S3); in situ XRPD patterns of $\mathbf{1}$ (Figure S4); TCVM movie for crystallization of $\mathbf{1}$ and 2 (Movie S1-S3). This information is available free of charge via the Internet at http://pubs.acs.org/.

\section{REFERENCES}

[1] Ushio, T.; Tamura, R. Angew. Chem. Int. Ed. 1996, 35, 2372-2374.

[2] Tamura, R.; Takahashi, H.; Hirotsu, K.; Nakajima, Y.; Ushio, T.; Toda, F. Angew. Chem. Int. Ed. 1998, 37, 2876-2878. [3] Jacques, J.; Collet, A.; Wilen, S. H. Enantiomer, Racemates and Resolution, Krieger: Malabar, 1994.

[4] Coquerel, G. Top. Curr. Chem. 2006, 269, 1-51.

[5] Tamura, R.; Fujimoto, D.; Lepp, Z.; Misaki, K.; Miura, H.; Takahashi, H.; Ushio, T.; Nakai, T.; Hirotsu, K. J. Am. Chem. Soc. 2002, 124, 13139-13153.

[6] Takahashi, H.; Tamura, R.; Fujimoto, D.; Lepp, Z.; Kobayashi, K.; Ushio, T. Chirality 2002, 14, 541-547.

[7] Fujimoto, D.; Tamura, R.; Lepp, Z.; Takahashi, H.; Ushio, T. Cryst. Growth Des. 2003, 3, 973-979. 
[8] Tamura, R.; Mizuta, M.; Yabunaka, S.; Fujimoto, D.; Ariga, T.; Okuhara, S.; Ikuma, N.; Takahashi, H, Tsue, H. Chem. Eur. J. 2006, 12, 3515-3527.

[9] Horiguchi, M.; Okuhara, S.; Shimano, E.; Fujimoto, D.; Takahashi, H.; Tsue, H.; Tamura, R. Cryst. Growth Des. 2007, 7, 1643-1652.

[10] Horiguchi, M.; Okuhara, S.; Shimano, E.; Fujimoto, D.; Takahashi, H.; Tsue, H.; Tamura, R. Cryst. Growth Des. 2008, $8,540-548$.

[11] Coquerel, G.; Tamura, R. In Disordered Pharmaceutical Materials; Descamps, M. Ed.; Wiley-VCH, 2016; pp 135-157. [12] Tamura, R.; Iwama, S.; Gonnade, R. G. CrystEngComm 2011, 13, 5269-5280.

[13] Tamura, R.; Iwama, Takahashi, H. Symmetry 2010, 2, 112 135 .

[14] Tamura, R.; Takahashi, H.; Fujimoto, D.; Ushio, T. Top. Curr. Chem. 2007, 269, 53-82.

[15] Tamura, R.; Ushio, T. In Enantiomer Separation: Fundamentals and Practical Methods; Toda, F., Ed.; Kluwer Academic Publishers: Dordrecht, The Netherlands, 2004; pp 135 163.

[16] Iwama, S.; Horiguchi, M.; Sato, H.; Uchida, Y.; Takahashi, H.; Tsue, H.; Tamura, R. Cryst. Growth Des. 2010, 10, 26882675.

[17] Gonnade, R. G.; Iwama, S.; Mori, Y.; Takahashi, H.; Tsue, H.; Tamura, R. Cryst. Growth Des. 2011, 11, 607-615.
[18] Gonnade, R. G.; Iwama, S.; Sugiwake, R.; Manoj, K.; Takahashi, H.; Tue, H.; Tamura, R. Chem. Commun. 2012, 48, 2791-2793.

[19] Iwama, S.; Kuyama, K.; Mori, Y.; Gonnade, R. G.; Suzuki, K.; Hughes, C. E.; Williams, P. A.; Harris, K. D. M.; Veesler, S.; Takahashi, H.; Tsue, H.; Tamura, R. Chem. Eur, J. 2014, 20, 10343-10350.

[20] Manoj, K.; Tamura, R.; Takahashi, H.; Tsue, H. CrystEngComm 2014, 16, 5811-5819.

[21] Manoj, K.; Takahashi, H.; Morita, Y.; Gonnade, R. G.; Iwama, S.; Tsue, H.; Tamura, R. Chirality 2015, 27, 405-410.

[22] Iwama, S.; Takahashi, H.; Tsue, H.; Tamura, R. Cryst. Growth Des. 2015, 15, 3052-3062.

[23] Uchida, Y.; Iwama, S.; Coquerel, G.; Tamura, R. Chem. Eur. J., 2016, 22, 11660 - 11666

[24] Astier, J. -P.; Veesler, S. Cryst. Growth Des. 2008, 8, 4215-4219.

[25] S. Veesler, L. Lafferrère, E. Garcia and C. Hoff, Org. Process Res. Dev., 2003, 7, 983-989.

[26] Dharmayat, S.; Hammond, R. B.; Lai., X.; Ma, C.; Purba, E.; Roberts, K. J.; Chen, Z-P.; Martin, E.; Morris, J.; Bytheway, R. Cryst. Growth Des. 2008, 8, 2205-2216.

[27] Coquerel, G.; Sanselme, M.; Lafontaine, A. WO 2012/136921. 
In situ Observation of Polymorphic Transition during Crystallization of Organic Compounds Showing Preferential Enrichment by Means of Temperature-Controlled Video-Microscopy and Time-Resolved X-Ray Powder Diffraction

Hiroki Takahashi, 'Sekai Iwama, Simon Clevers, Stéphane Veesler, Gérard Coquerel, Hirohito Tsue, Rui Tamura

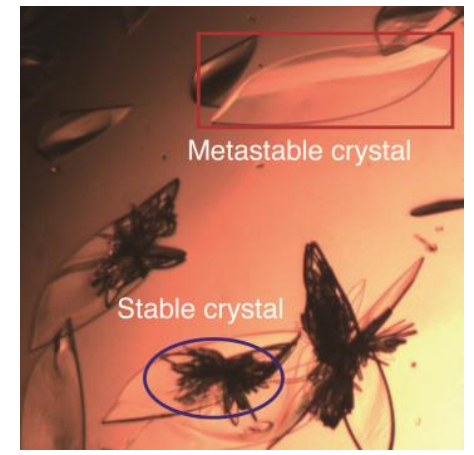

The stable crystals with a dendritic habit appeared by heterogeneous nucleation onto the metastable leaf-shaped crystals. This polymorphic transition, which was observed by means of temperature-controlled video-microscopy (TCVM) and time-resolved in situ Xray powder diffraction (XRPD), would be responsible for the occurrence of Preferential Enrichment. 
In situ Observation of Polymorphic Transition during Crystallization of Organic Compounds Showing Preferential Enrichment by Means of Temperature-Controlled Video-Microscopy and Time-Resolved X-Ray Powder Diffraction

Hiroki Takahashi, ${ }^{, 1}$ Sekai Iwama, ${ }^{2}$ Simon Clevers, ${ }^{3}$ Stéphane Veesler, ${ }^{4}$ Gérard Coquerel, ${ }^{3}$ Hirohito Tsue, ${ }^{1}$ Rui Tamura ${ }^{1}$

${ }^{1}$ Graduate School of Human and Environmental Studies, Kyoto University, Kyoto 6068501, Japan

${ }^{2}$ Faculty of Law, Meijigakuin University, Minato-ku, Tokyo 108-8636, Japan

${ }^{3}$ Normandie Université, SMS, EA 3233, Univ Rouen, Crystal Genesis Unit, 76821 Mont

Saint-Aignan Cedex, France

${ }^{4}$ CINaM-CNRS, Aix-Marseille Université, Campus de Luminy, F-13288 Marseille, France

Supporting Information 

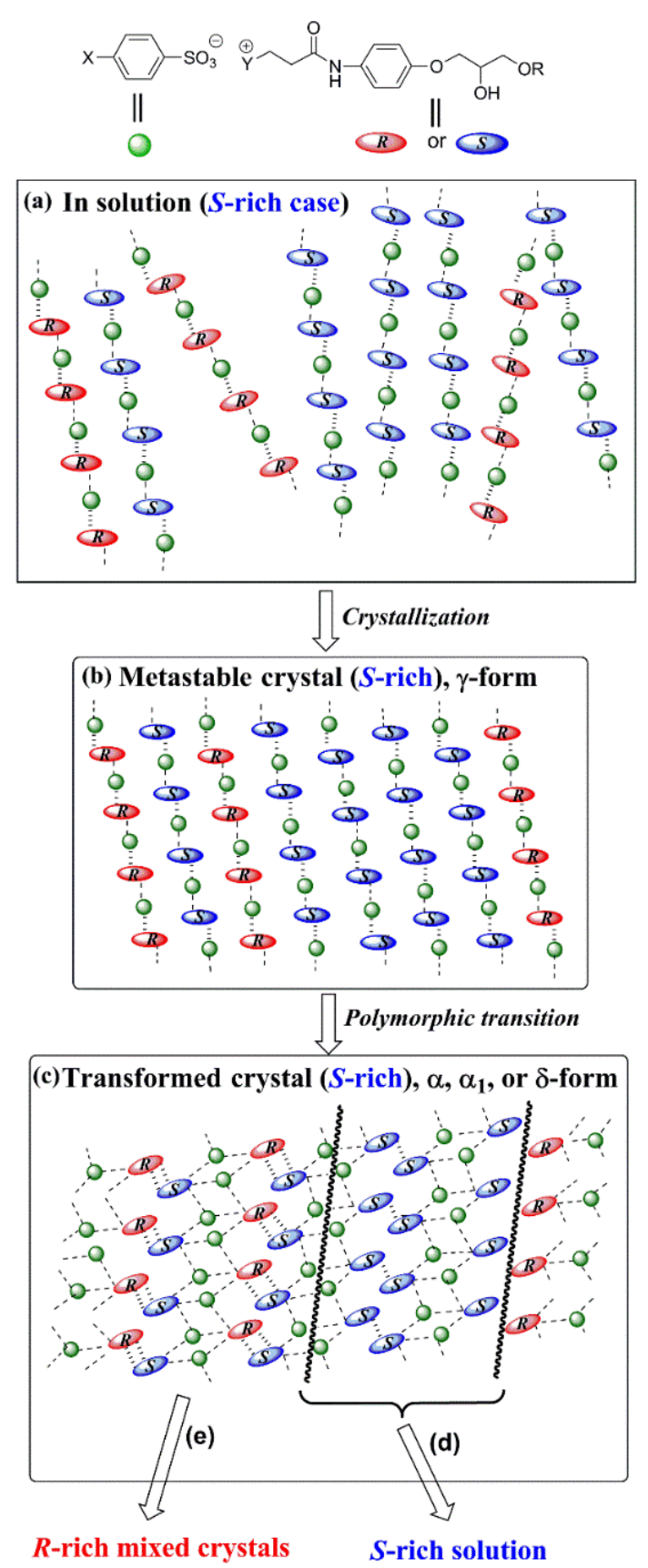

Figure S1. General mechanism of PE in the case of crystallization from a highly supersaturated solution of a slightly $S$-rich first-generation organic compound. Homochiral 1D molecular association a) in solution and b) in the metastable crystal, and heterochiral 2D molecular association c) in the transformed crystal after polymorphic transition, followed by d) selective redissolution of the excess $S$ enantiomer into the solution and e) deposition of nonracemic mixed crystals enriched with the opposite $R$ enantiomer. 

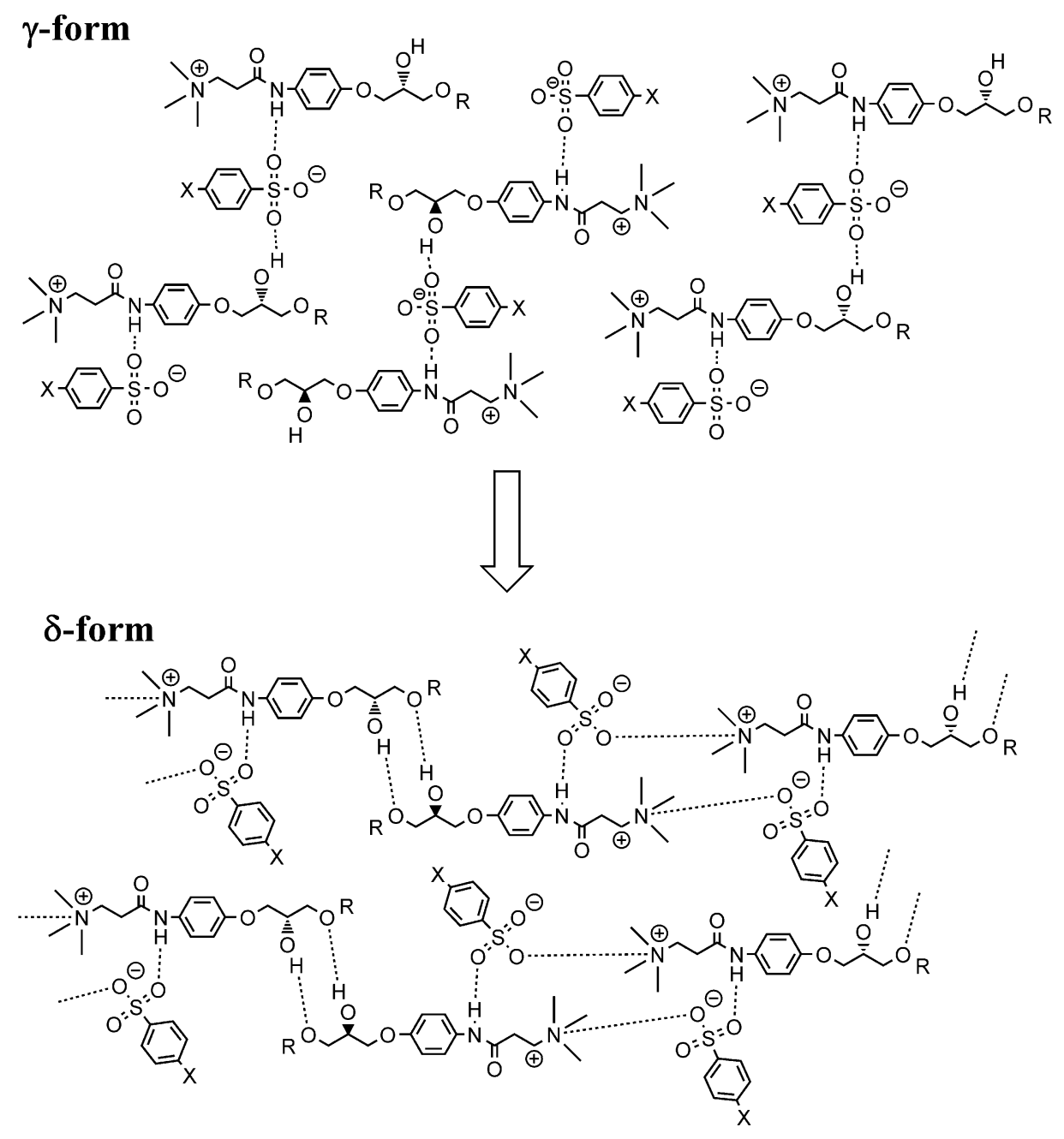

Figure S2. Schematic representation of the intermolecular interactions in the $\delta$ - and $\gamma$ form crystals. The $\delta$-form crystals were commonly found as a stable form for the compounds showing PE. 


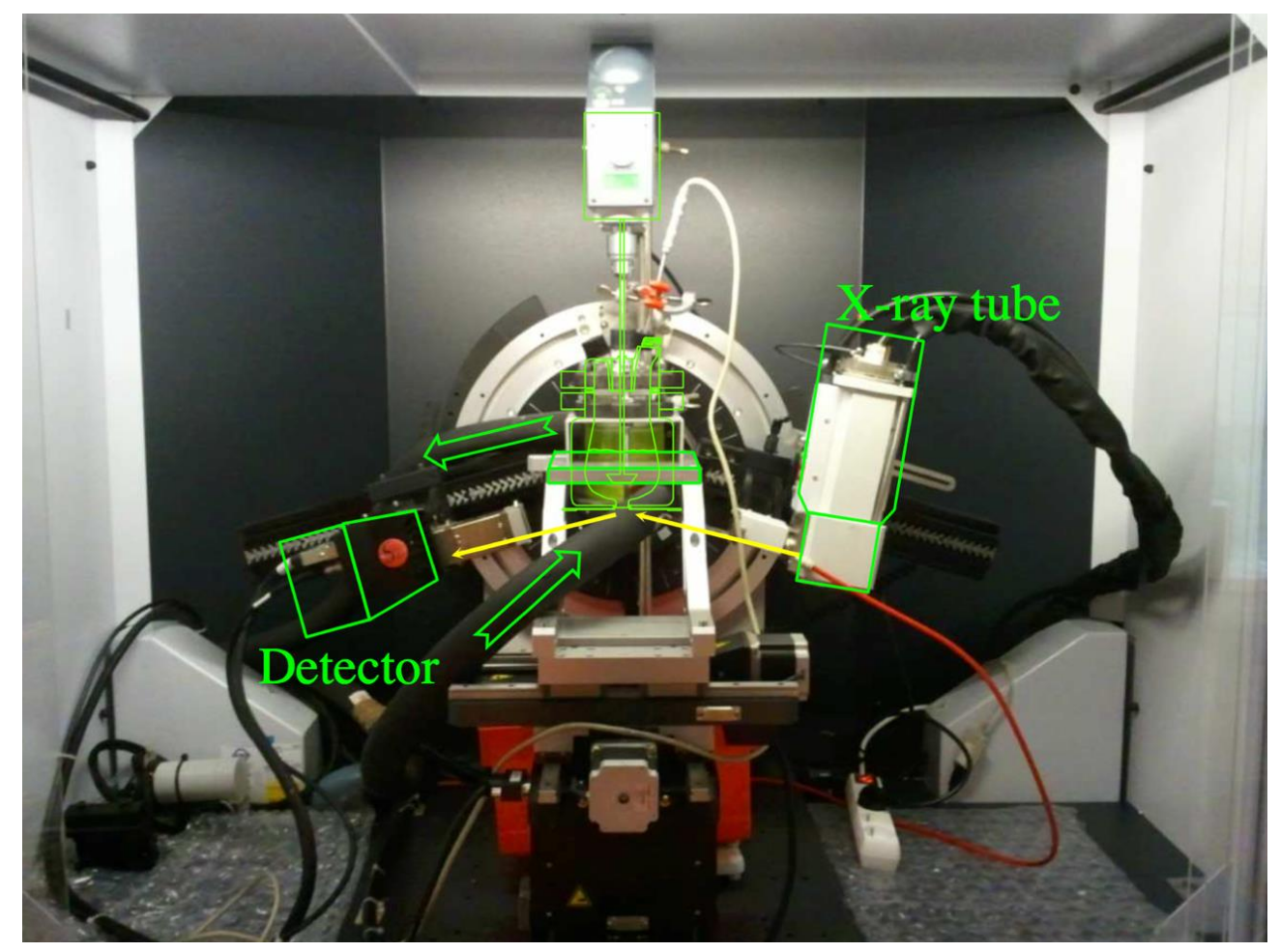

Figure S3. Overview of in situ X-ray diffractometer. The right and left sides are an X-ray source and a semiconductor detector, respectively. The observation cell is set in the cell holder. 

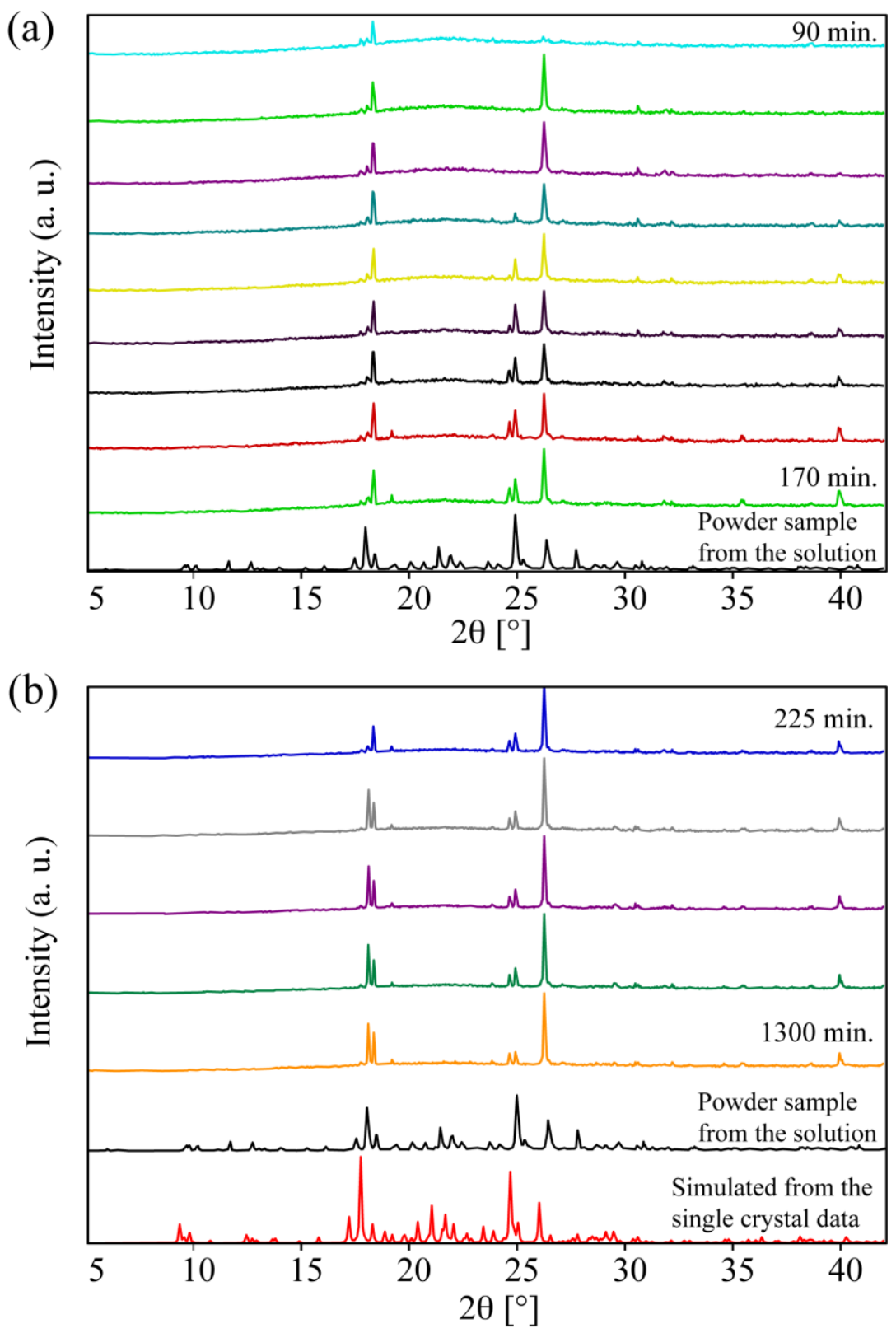

Figure S4. In situ XRPD patterns of 1. Conditions: In EtOH/2-PrOH (1/1 v/v, 11 fold supersaturation), at $10{ }^{\circ} \mathrm{C}$. (a) From 90 to 170 min with 9 min interval, and (b) 225 to 1300 min with 240 min interval. These in situ diffraction patterns were compared with that of the dry final powder sample and that simulated from the single crystal data $(\delta$ form) of racemic $\mathbf{1}$. 
Movie S1. TCVM movie for crystallization from a 10 fold supersaturated $\mathrm{EtOH} / 2-\mathrm{PrOH}$ $(1 / 1 \mathrm{v} / \mathrm{v})$ of 1 at 20 to $70{ }^{\circ} \mathrm{C}$. The duration of the crystallization process recorded is 114 $\min (6840 \mathrm{~s})$. Since the movie length is $66 \mathrm{~s}, 1 \mathrm{~s}$ in the movie corresponds to $103 \mathrm{~s}$ in the actual time.

Movie S2. TCMV movie for crystallization from a 20 fold supersaturated EtOH of 2 at $20{ }^{\circ} \mathrm{C}$ for $1 \mathrm{~min}$, followed by heating to $70^{\circ} \mathrm{C}$. The duration of the crystallization process recorded is $417 \mathrm{~min}(25020 \mathrm{~s})$. Since the length of the movie is $72 \mathrm{~s}, 1 \mathrm{~s}$ in the movie corresponds to $4320 \mathrm{~s}$ in the actual time.

Movie S3. TCMV movie for dissolution behavior of deposited crystals of 2 in EtOH by heating from 20 to $70{ }^{\circ} \mathrm{C}$. The initial crystallization conditions are the same as in Movie $\mathrm{S} 2$. The duration of the dissolution process recorded is $16 \mathrm{~min}$ (960 s). Since the length of the movie is $9 \mathrm{~s}, 1 \mathrm{~s}$ in the movie corresponds to $106 \mathrm{~s}$ in the actual time. 